\title{
Node Relocation Techniques for Wireless Sensor Networks: A Short Survey
}

\author{
Mahmood ul Hassan ${ }^{1}$, Amin Al Awady ${ }^{4}$ \\ Department of Computer skills, Deanship of preparatory \\ year, Najran University \\ Najran, Kingdom of Saudi Arabia
}

\author{
Khalid Mahmood ${ }^{2}$ \\ College of Science and Arts, Department of Information \\ Systems, King Khalid University \\ Tehama Branch, Kingdom of Saudi Arabia
}

\author{
Shahzad $\mathrm{Ali}^{3}$ \\ Department of Computer Science \\ Jouf University \\ Tabarjal, Kingdom of Saudi Arabia
}

\begin{abstract}
Sensor nodes in a sensor network often operate in harsh and challenging environments and this leads to frequent failure of sensor nodes. Failure of sensor nodes leads to partitioning in the network connectivity. For significant effectiveness of applications of sensor networks, the inter-sensor connectivity among sensors is vital. Some sensors are also involved in sustaining the flow of information from the sensor to unapproachable end users. The network can be split up into multiple incoherent blocks and cease working due to physical damage or onboard energy depletion. To deal with such scenarios, a plethora of node repositioning techniques are proposed in the literature. In this article, the recent and up to date mode of research on dynamic sensor repositioning in WSN is discussed. This article classifies sensor repositioning methods into on-demand and post-deployment repositioning based on whether the optimization is accomplished at deployment time or while the network is functioning.
\end{abstract}

Keywords—Node failure; sensor node; post-deployment; ondemand relocation; internode connectivity

\section{INTRODUCTION}

Wireless Sensor Network (WSN) is marked as an influential technology and considered as a well-established research area for its wide range of applications. WSN while having certain lower energy and reasonable densely inactive compact mobile nodes is typically organized well in the practices like environment reconnaissance, to assign data and manage communications amongst one another via radio-based technology [3]. WSN is known to be very useful in the environments where human intervention is mostly impractical like wild fire detection, battlefield surveillance, deep ocean exploration, etc. [11]. Mainly, these sensor nodes applications are associated with armed forces, households, or medical care. Moreover, in the armed services, for instance, through its timely practice, defective endurance quality, and independent operation, WSN has revealed its extraordinary applicability relating the systems of armed forces involving inspection, scheming, communication, targeting, and commanding. In health applications, these nodes help monitor the patients and support the patients with special needs (disabled). Besides, these sensor nodes are influential in the areas of commerce and finance like in supply chain management, etc. Moreover, they can also be utilized for monitoring the areas affected by disaster [10].

Fig. 1 shows the sensors random deployment in a region. All of these nodes are responsible for performing the given task independently in a distributed manner and communicate with each other using multi-hop communication. Sensor nodes send back the sensed data to the sink node in a multi-hop fashion as shown in Fig. 1. Eventually, this data is sent to the user by means of internet afterwards [3].

The dynamic relocation of sensors in the operation of the network is very significant to enhance its performance [25]. During the operation of WSN, some of the redundant sensors located at different locations will likely be repositioned in order to replace the sensors with depleted batteries for rectification of network stability [26].

Besides, this type of dynamic repositioning might be appropriate in a mechanism that supports the target movement; also the moveable ones [1]. To further clarify, it approaches forth, eventually gets feasible to reposition particular sensor nodes close-by to the target to attain the improvement of node's data accuracy. In relevant applications [4] and in order to maintain the availability, installing base-station into secure position from ambiguous targets like a tank of an enemy, at the present, could be a better accomplishment [13]. The resolution of the disputation to reposition dynamic sensor node has been analyzed in $[22,23]$.

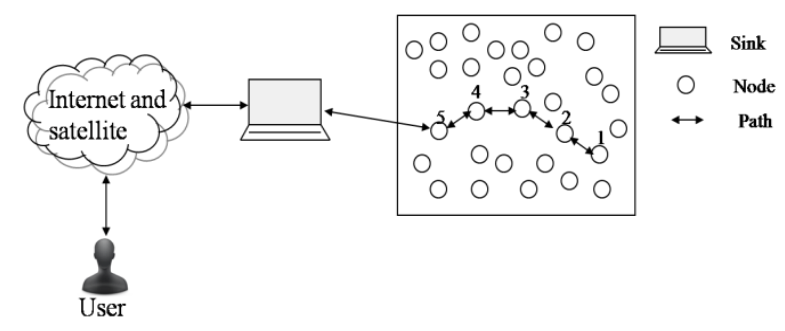

Fig. 1. Wireless Sensor Network (WSN). 
A variety of node positioning/relocation techniques are present in the literature. In order to facilitate the research community, it is important to provide them with a comprehensive state-of-the-art knowledge about the recent proposed mechanisms for node relocation. The main contributions of our article can be summarized as follows:

- Varieties of techniques in the literature on dynamic node positioning are characterized by explaining the consequences of dynamic node relocation in wireless sensor network field. Consequently, during the usual network operation or after deployment, this may turn into a practical standard to achieve better improvement in the performance.

- In the sensor node repositioning, it is conceivable to handle the dynamic variation in the network resource surrounding environment as it is dissimilar from the initial deployment. In this article many technical issues are highlighted for sensor node relocation. These technical issues define where to move the sensor node and how to accomplish the network when the sensor node is mobile?

- Several dynamic node positioning techniques are compared and reviewed based on their application, objective, and methodology. As a result, it is supposed that the sensor nodes which are movable can probably be dynamically relocated in order to fill the connectivity and coverage by managing the variations in the user importance.

- The problem of managing multi-node reposition is acknowledged as an open research area and an important attention is paid to this interesting and challenging area.

The rest of the paper is organized as follows. Nodes repositioning issues are summarized in section II. Dynamic node repositioning schemes are discussed in section III and subsequently, section IV concludes this paper.

\section{Node Repositioning IsSUES}

In order to improve the network performance, it is necessary to dynamically relocate the sensor nodes while the network is operational. For instance, because of consumption of batteries many sensor nodes stop functioning in the neighborhood of base-station, consequently to improve the lifetime of network replacing the dead sensor nodes by some redundant sensor nodes from other monitored region can be one solution. The dynamic relocation is much valuable in those applications where the target is movable. For example, to increase the sensor's node fidelity, few of the sensor nodes might be relocated in the sensing region, e.g. the relocating of the enemy tank to the safer region by confirming its availability. Therefore it is very challenging to relocate the sensor nodes during the regular network operation. In response to environment-based or network incentives, such type of relocation is followed. So the continuous monitoring of the nodes in the sensing region is necessary.

\section{Dynamic Node Relocation Schemes}

Purposefully, for dynamic sensor node's relocation, various techniques have been introduced in the research. These techniques can be categorized into two different types as shown in Fig. 2. The post-deployment relocation (established at the completion of repositioning) undergoes relocation only through the procedure that is implemented at the initiation while the on-demand relocation is the movement carried out by the nodes at any moment of the repositioning of the sensor nodes.

\section{A. Post Deployment Repositioning}

Generally, the deployment of WSN in a conventional manner involves locating the sensor nodes either randomly or by the ad-hoc procedure for the appropriate and convenient outdoor application [12]. However, a sensor node or piece of equipment in an industrial setup is designed to be positioned at the same point for several years. Therefore, it is not possible to contemplate the luxury of relocating nodes in a random way. Additionally, connectivity and coverage are essential for sending information to the required destination effectively. To overcome such difficulties, systematic and well-planned design and arrangement is required. This arrangement and planning helps in the reduction of cost and is ultimately time-saving for designing a WSN. Hence, it is necessary to organize and simulate the WSN before deploying it.

VECtor-centered technique (VEC), Minimax technique, and VORonoi-centered technique (VOR) [24] involves the conceptualization of $[6,8]$ associated with this type. There is a firm bond of all these three techniques to sensor node's Voronoi polygon or position in which the sensor node or the point that is in proximity rather than to the sensory border. In this scenario, the VECtor-based technique can be handled by applying Coulomb's law as the corresponding procedure so as to demonstrate deterrence amongst electrostatic components. The sensor node that is meant to dispossess a constituent of Voronoi polygon of the node subsequently is aimed to get eliminated from other sensors close by via vigour analogous to interlude that it acquires probably from sensors or polygon's angular points.

Fig. 3 shows how the Voronoi technique detect the coverage hole and how to point out the hole size.

Knowingly, for reducing the covered area for the route, [8] has suggested a technique depending on the proxy that lacks the physical movement of the nodes, apart from the computed destination. At this juncture, it is found that the author emphasis to a great extent on the methodology of authentication of movable or stationary sensors. In this regard, the movable nodes are responsible for occupying the level of that point where sensors are missing in distributed pattern evaluated by stationary sensors, indicating that movable sensors are in the consistent mobility and locate stationary sensors in the form of an agent. Following this frame of reference, there will be a major depletion in distance whether from the totality or the calculated set of numbers in which the mobile sensors [10] direct alongside in retaining the coverage at equal rate [7]. By implementing it using a methodology 
approved from a widely accepted design for the load balance amongst the sensors in conformations number on parallel computing through the process is separated into multiple parts, concurrently carried out various processors. This strategy, successively, is used in multi-cluster WSN in which the square cell that forms 2-D mesh will specify each single cluster and several nodes added on the single cell shall categorize cluster's load. The position in an inter-connection either in vertical or horizontal indices and the sensor node quantity in its cluster signify that the only communication the cluster-head could have it is by using its same location in other nearby cells. Consequently, the corresponding attained coverage is relevant to the problem of balancing the level of energy to stabilize the distribution of nodes among clusters. Fig. 4 shows the post deployment repositioning techniques.

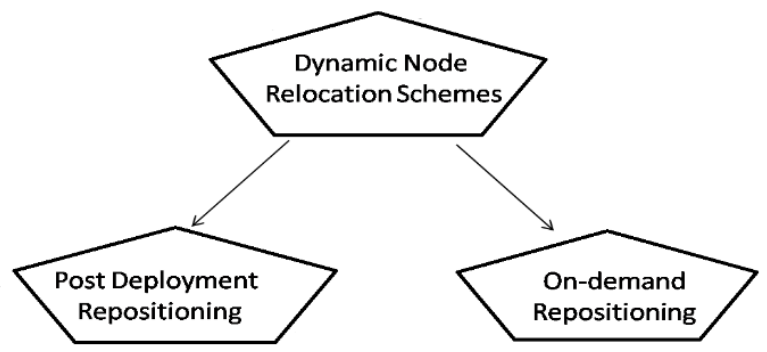

Fig. 2. Categories and Evolution of Dynamic Sensor Node Relocation.

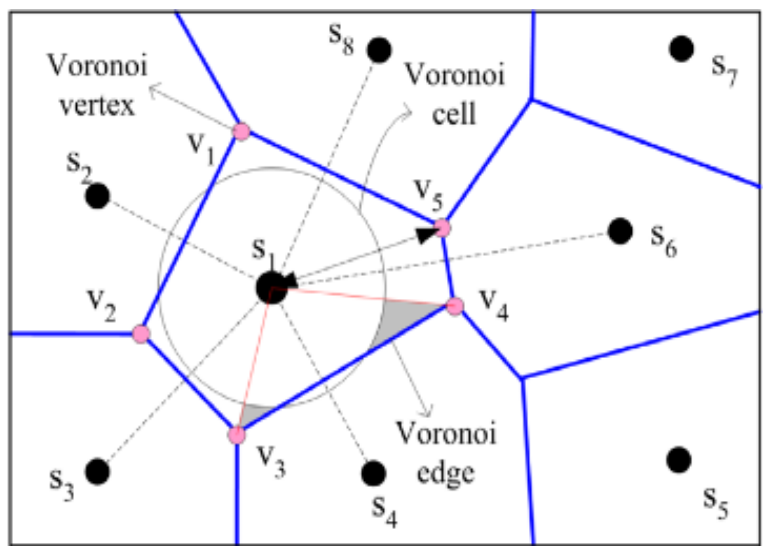

Fig. 3. Voronoi Diagram for the Detection of the Coverage Hole and the Hole Size [6-8].

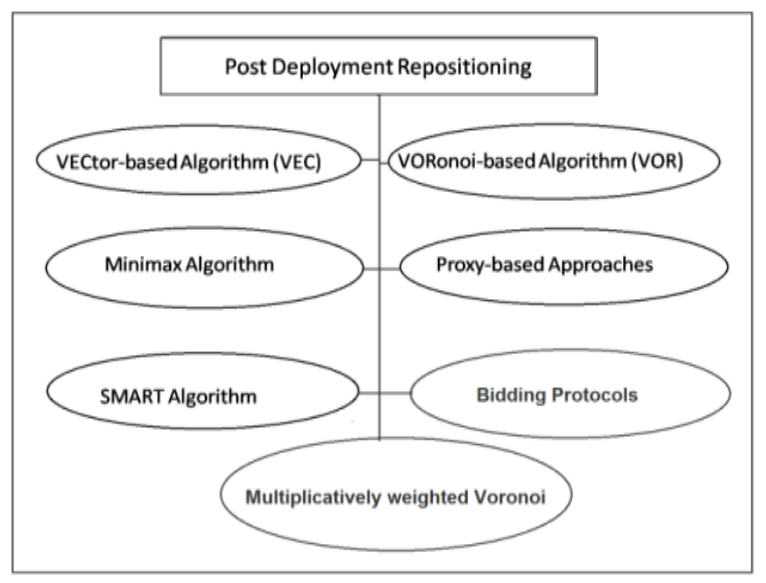

Fig. 4. Post Deployment Relocation Schemes in WSN.

\section{B. On-Demand Relocation}

The effectual network for relocation/repositioning emerges as the objective of this category. The effectiveness at the outset of network application lessens essentially for the faulty sensor node. Besides, the essence of the output can also be affected by several fluctuations in the requirements of the application. Moreover, in other cases, it is assumed that sensor nodes should move methodically for keeping the network arrangement efficient. During sensor relocation, rather than repositioning the sensors at the deployment stage, a definite number of sensors are alternatively moved by on-demand relocation to reinforce the specific performance metrics [21, 30].

The existing connectivity restoration techniques $[14,28]$ mainly consist of two steps i.e. failure detection and recovery. Failure detection is used to discover a node or a component failure. It can be classified into single and collaborative diagnosis depending on the number of nodes involved. Single diagnosis can further be categorized in to self and non-selfdiagnosis. In self-diagnosis, a node can only determine some of its component failures. For instance, some of the faults can be determined by the actor node [5] itself such as loss of actor action ability, remaining battery power, communication faults, etc. Non-self-diagnosis involves one of the neighbor actor nodes detecting the failed actor based on the heartbeat messages that nodes exchange with each other as part of the network operation. For example, approaches like PADRA [14, 21] involve one of the neighbors detecting the failure. On the other hand, collaborative diagnosis employs more than one node to determine the failure of a particular actor. It can further be categorized based on the number of nodes involved. Whereas, the MPADRA employs two actor nodes and RIM [22] involves all the neighbors in order to detect the failure.

In [21] authors have addressed the substitution of failed node by putting forward a mechanism called Cascaded Movement, in which, nodes use a recurrent substitution towards sensor close to another redundant one.

Fig. 5 shows the Cascaded Movement where the sensor s1 characterizes redundant sensor. Moreover, sensors s4 and s1 are faulty and redundant sensors. The sensor s3 after finding s4 failure will be searching for the redundant sensor. Using the sensor s2, as per presumption, the sensor s3 discovers $s 1$ that is the redundant node, and the failed node will be superseded by the cascaded movement of sensors s3, s1, and s2, latterly (movements of s1-s2, s2-s3, and s3-s4 occur instantaneously).

Correspondingly, connectivity is taken into account by the further mechanism whereas demonstrated in [15, 23], one technique prefers on keeping up the 2-degree connectivity even under node or link failure depending on the mobility of a subset of the sensor node. While the relocation time can be reduced by using cascaded movement; due to disarrangement of the redundant sensor node, the reviewers are incapable of reducing the time of finding out the redundant sensor node.

In the meantime, post-deployment coverage and connectivity were studied by [20] and [21]. With Connected Coverage and Latency-aware Actor placement (COCOLA), architecture of the network is designed in such a way that is 
ranked orderly. Following the aforementioned methodology, high-tiered sensors are relocated, progressively, in order to maximize the coverage but without extension to the data route of a sensor on $1^{\text {st }}$ tier. Purposively, this is for maintaining the desirable bound on latency of data [9]. In spite of that, the influence exerted by faulty sensor note remains unhandled by both COCOLA [21] and $\mathrm{C}^{2} \mathrm{AP}[2]$.

In [22] authors have proposed RIM (Recovery through Inward Motion) and NN (Nearest Neighbor) techniques; both of which are conformed to the avid heuristics. As a result of failure of node in NN, it will proceed to progress towards Failure Neighbor Node (FNN) being one in close proximity to $\mathrm{F}$ position is for restoring the connectivity failure immediately. As a result, a movement of the highly adjacent node among the FNN neighbors takes place, which, subsequently, will position as a replacement of FNN and ultimately the neighboring FNN responds to its elimination.

Fig. 6 provides a diagrammatic representation of working of NN technique in which there exists a topology hole, once node $\mathrm{F}$ fails. This is portrayed in the Fig. 6(a). A notification message is sent from node $\mathrm{B}$ to $\mathrm{D}$ and $\mathrm{C}$ previous to it makes a move and $\mathrm{H}, \mathrm{G}$ and $\mathrm{A}$ once it arrives at another location. Moreover, as shown in the Fig. 6, the parts (b) \& (c) refer to the interconnectivity of network subsequent to the replacement of node F by B and also B substituted by D. As per illustrated in (part d) it is just node $E$ that gets affected and takes over the initial position of $\mathrm{D}$.

For the purpose of establishing network connectivity, RIM as illustrated in Fig. 7, a procedure is established via inner movement that acquires a prominent method of displaying the inward direction of neighbors of $\mathrm{F}$ node to the particular point after the failure occurs in order to set up an interconnection amongst the nodes. This phenomenon is determined by neighbor nodes instantaneously influenced by the failure of $\mathrm{F}$ node, and subsequently, once approaching one another, internode connectivity will be restored aimed to its former place before the breakdown.

The repositioning is done by recursion to any sensor node that is not relevant to the neighbor node's movement, supposedly, nodes that have moved out towards the damaged one. NN consequently ceases its operation either due to the absence of the neighbor node for a dead sensor (approaching the network borderline), or else, after every node's movement in the network. Provided that RIM enforces the list of one-hop neighbor, the procedure in NN technique, sequentially, postulates that each node should be aware for its two-hop neighbor, subsequently, it can empower to discover the neighbor in the close proximity earlier than the breakdown of $\mathrm{F}$ sensor node. In this scenario, there is no relevance of NN and RIM with the aftermath that probably appears in restoring the connectivity of the enclosed network.

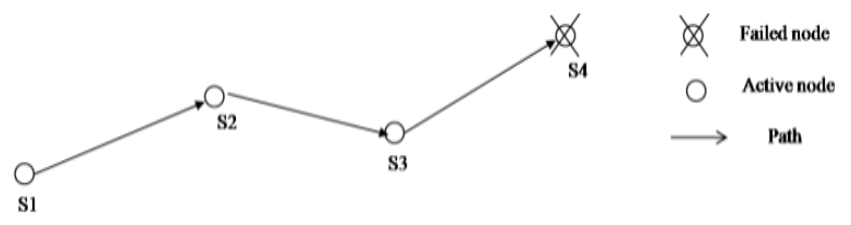

Fig. 5. Sensor Nodes Cascaded Movement after Failure.
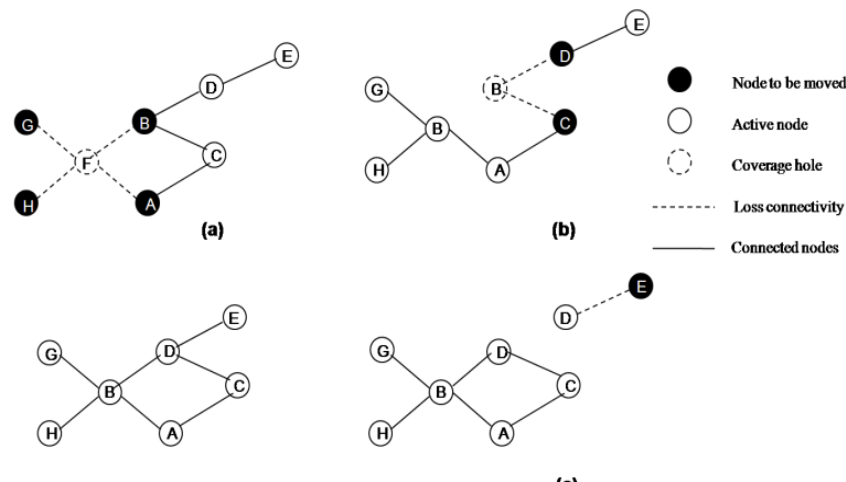

(d)

(c)

Fig. 6. The Example Illustrates How NN Procedure Reestablishes Connectivity by Substituting Failed Sensor with its Adjacent Neighbor and Iterating this Procedure for Every Sensor that Plants its Location.

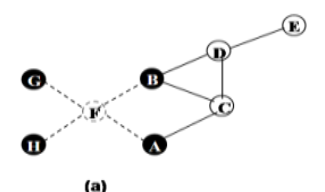

(a)

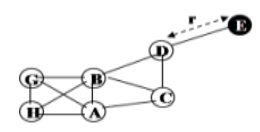

(d)
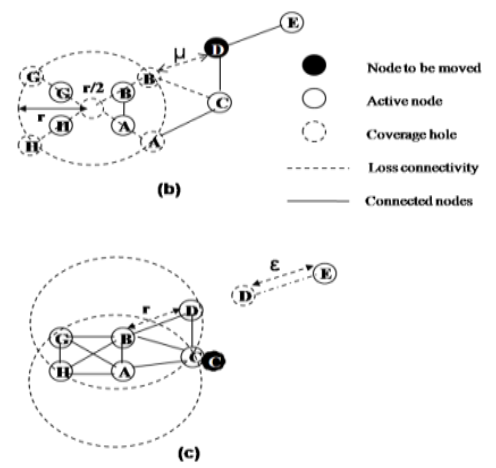

Fig. 7. (a)-(d) is an Example of the Restoration Process of RIM; Every Shaded Sensor Node Moves Depending on its Neighboring Position, Represented in the Circles of Dotted Line.

This cascaded repositioning could be prevented by $\mathrm{C}^{3} \mathrm{R}$ procedure, also known as Coverage-Conscious Connectivity Restoration [16]. Despite the fact that if replacing the neighbor node by other is restore the connectivity among nodes, it clearly modifies the coverage hole in the sensor's area partially in point of fact, either in the network's interior part or mobile sensor relocation along with border to tackle efficiently with connectivity and coverage from the sensor node's breakdown. The sensors, instead of network topology reconfiguration, work back and forth to substitute failed sensor so as to provide sporadic recovery rather than a permanent one.

Fig. 8 illustrates how $\mathrm{C}^{3} \mathrm{R}$ operates based on the patterned network. Moreover, it can be seen that the capacity of neighbor node's connectivity with $\mathrm{n} 9$ sensor node will be diminished and rapidly goes through the internal movement after detecting the defect of $n$ 9. This is carried out to design a pattern that overcomes the breakdown of the node. In addition, as a matter of fact, that $\mathrm{n} 11$ sensor node is lying in close range to $\mathrm{n} 9$, it swifts speedily than other neighboring nodes towards $\mathrm{n} 9$. Besides, n11 serves as a coordinating node as represented in Fig. 8(b). In this scenario, several nodes will assemble the scheduled data from $\mathrm{n} 11$ and go back to the respective places excluding $\mathrm{n} 2$ node because it serves as an initiating node organized for restoration and acquire a strong overlapping coverage as indicated in Fig. 8(c). Fig. 8(d to g), furthermore, depict to and fro motion of various neighbors of $\mathrm{n} 9$ sensor node successively for the recovery of the network from failure of 
node $\mathrm{n} 9$. This approach noticeably unfolds numerous periodic changes in the inter-connection and possibly can inflict a considerable amount of overhead. It is therefore unambiguous about this mechanism being transient in terms of anticipating the efficiency of the spare nodes. $C^{3} \mathrm{R}$, furthermore, handles only a single failure individually and doesn't cope with the simultaneous and multiple node failures.

The DCRS (Distributed Connectivity Restoration Strategy) [20] has been put forward to deal with the faulty critical node. The mechanism is illustrated in Fig. 9. Due to energy limitation of the sensor nodes, the energy overhead of the repairing process should be reduced to prolong the network's lifespan [27]. For implementation, authors initially designed an algorithm for the identification of two critical nodes that merely rely on the factual data of position of the one-hop and a few two-hop neighbors, and a methodology of choosing the pertinent backup has been introduced for every critical node. A distributed Resource Constrained Recovery (RCR) technique illustrates the procedure of restoring the network connectivity by the strategic relocation of nodes [17].
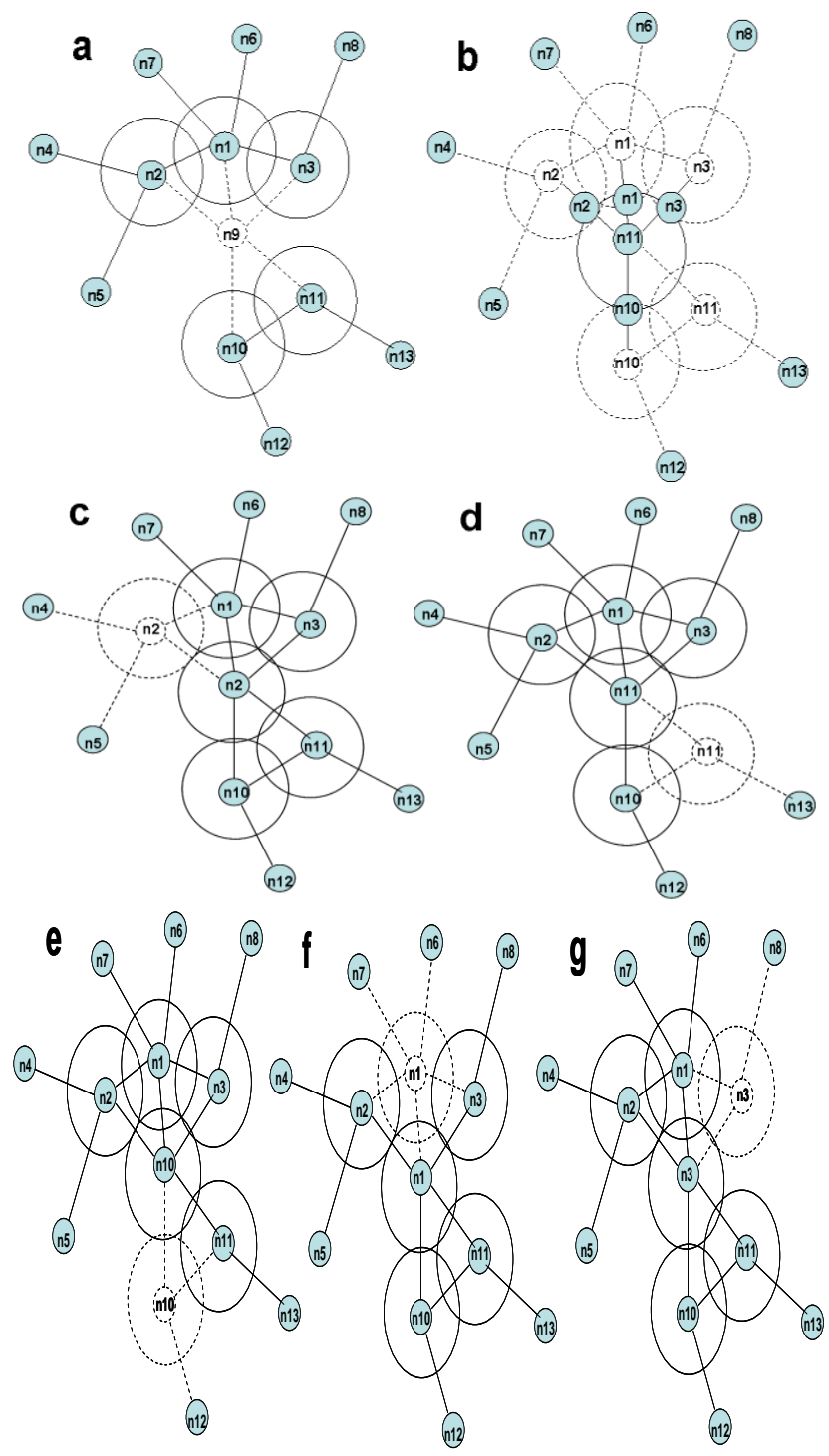

Fig. 8. Working Flow of $\mathrm{C}^{3} \mathrm{R}$ Technique.
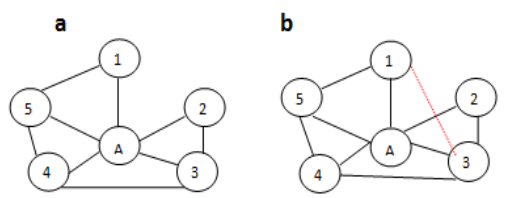

c
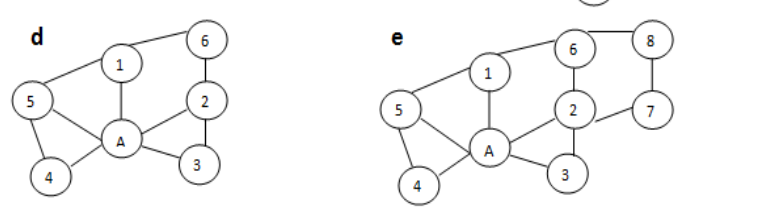

Fig. 9. The DCRS Technique Illustration.

The GSR is proposed that exploits form of deployment region to facilitate the restoration of the connectivity in the partitioned WSN in distributed pattern. This approach disintegrates the area of deployment into the equivalent 2D skeleton outline, with a mobile transmission that is occupied by the survival of the disjoint parts to recover the connectivity [19].

The RRLC-CFP (Restore Relay Lost Connectivity using Concentric Fermat Points) algorithm is proposed for the network restoration which is based on the transmitted node's placement. In this technique network partitioned due to multinode failure, the problem is considered and solved by a novel approach named Concentric Fermat Points. This approach is used in data transmission for the reduction of the distance of data transmission among the nodes in order to boost the life time of the network [18].

So in this section, different connectivity restoration techniques were presented based on on-demand relocation. In the next section, we present a comparison of all the existing techniques presented in this paper and summarize all the information in tabular form.

Fig. 10 shows the list of on-demand repositioning techniques discussed in this paper.

\section{Design Goals for Optimization of a Node Relocation Algorithm}

While designing a new algorithm for node relocation, following points must be addressed. The descriptions of these points are illustrated in Table I.

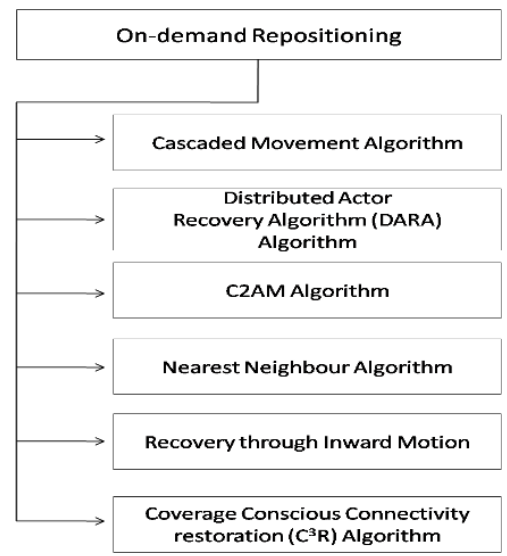

Fig. 10. On-Demand Relocation/Repositioning Schemes. 
TABLE. I. CORE OPTIMIZATION POINTS FOR NODE RELOCATION

\begin{tabular}{|l|l|}
\hline $\begin{array}{l}\text { Optimization } \\
\text { Point }\end{array}$ & Description \\
\hline $\begin{array}{l}\text { Fast hole } \\
\text { healing }\end{array}$ & $\begin{array}{l}\text { If any of the sensor node fails, or there is a network hole, } \\
\text { then neighbour of the failed node immediately recover this } \\
\text { network hole. The technique for identifying network hole } \\
\text { must be fast to sustain the network coverage and } \\
\text { connectivity for the recovery process. }\end{array}$ \\
\hline $\begin{array}{l}\text { Minimum } \\
\text { message } \\
\text { overhead }\end{array}$ & $\begin{array}{l}\text { In order to restore the network connectivity, this method } \\
\text { shows the total number of exchange messages by all the } \\
\text { sensor nodes. The lower the number of messages the } \\
\text { lower the overhead. }\end{array}$ \\
\hline $\begin{array}{l}\text { Energy } \\
\text { efficiency }\end{array}$ & $\begin{array}{l}\text { Energy efficiency is the most important factor of wireless } \\
\text { sensor network [29]. If the sensor nodes are the mobile } \\
\text { nodes then the primary design objective is to enhance the } \\
\text { energy level during the movement and transmission of } \\
\text { sensor nodes in sensing region. Different energy efficient } \\
\text { algorithms or techniques are used for computing optimum } \\
\text { ranges of transmission in order to make the network } \\
\text { energy efficient }\end{array}$ \\
\hline
\end{tabular}

TABLE. II. DYNAMIC RELOCATION SCHEMES COMPARISON

\begin{tabular}{|c|c|c|c|c|c|c|}
\hline : & $\begin{array}{l}\text { Optimiza } \\
\text { tion } \\
\text { objective }\end{array}$ & $\begin{array}{l}\text { Relocat } \\
\text { ion } \\
\text { Techni } \\
\text { que }\end{array}$ & $\begin{array}{l}\text { Type } \\
\text { s of } \\
\text { nodes }\end{array}$ & $\begin{array}{l}\text { Mobili } \\
\text { ty of } \\
\text { Sensor } \\
\text { S }\end{array}$ & $\begin{array}{l}\text { Num } \\
\text { ber of } \\
\text { hops }\end{array}$ & $\begin{array}{l}\text { Limitations/Con } \\
\text { straint }\end{array}$ \\
\hline$\underset{\infty}{\stackrel{ \pm}{\infty}}$ & $\begin{array}{l}\text { Restorati } \\
\text { on of } \\
\text { Connecti } \\
\text { vity }\end{array}$ & $\begin{array}{l}\text { Direct } \\
\text { techniq } \\
\text { ue }\end{array}$ & $\begin{array}{l}\text { Senso } \\
\mathrm{r} \\
\text { nodes }\end{array}$ & Robots & 2 & $\begin{array}{l}\text { Time of } \\
\text { convergence, no } \\
\text { deliberate } \\
\text { coverage }\end{array}$ \\
\hline $\begin{array}{l}n \\
\pm\end{array}$ & $\begin{array}{l}\text { Restorati } \\
\text { on of } \\
\text { Connecti } \\
\text { vity }\end{array}$ & $\begin{array}{l}\text { Shifted } \\
\text { techniq } \\
\text { ue }\end{array}$ & $\begin{array}{l}\text { Data } \\
\text { collec } \\
\text { tor }\end{array}$ & Robots & 2 & $\begin{array}{l}\text { Time of } \\
\text { convergence, } \\
\text { doesn't reflect } \\
\text { coverage }\end{array}$ \\
\hline 0 & $\begin{array}{l}\text { Restorati } \\
\text { on of } \\
\text { Connecti } \\
\text { vity }\end{array}$ & $\begin{array}{l}\text { Shifted } \\
\text { techniq } \\
\text { ue }\end{array}$ & $\begin{array}{l}\text { Senso } \\
\mathrm{r} \\
\text { nodes }\end{array}$ & $\begin{array}{l}\text { Mobile } \\
\text { sensor } \\
\text { s }\end{array}$ & 2 & $\begin{array}{l}\text { Connectivity not } \\
\text { included }\end{array}$ \\
\hline$\approx$ & Coverage & $\begin{array}{l}\text { Direct } \\
\text { techniq } \\
\text { ue }\end{array}$ & $\begin{array}{l}\text { Senso } \\
\mathrm{r} \\
\text { nodes }\end{array}$ & $\begin{array}{l}\text { Mobile } \\
\text { sensor } \\
\text { s }\end{array}$ & 1 & $\begin{array}{l}\text { Connectivity not } \\
\text { considered }\end{array}$ \\
\hline సิ & $\begin{array}{l}\text { Restorati } \\
\text { on of } \\
\text { Connecti } \\
\text { vity }\end{array}$ & $\begin{array}{l}\text { Shifted } \\
\text { techniq } \\
\text { ue }\end{array}$ & $\begin{array}{l}\text { Senso } \\
\text { rs }\end{array}$ & $\begin{array}{l}\text { Sensor } \\
\mathrm{s}\end{array}$ & 2 & $\begin{array}{l}\text { Time of } \\
\text { convergence, } \\
\text { coverage not } \\
\text { included }\end{array}$ \\
\hline 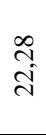 & $\begin{array}{l}\text { Restorati } \\
\text { on of } \\
\text { Connecti } \\
\text { vity }\end{array}$ & $\begin{array}{l}\text { Direct } \\
\text { techniq } \\
\text { ue }\end{array}$ & $\begin{array}{l}\text { Senso } \\
\text { rs }\end{array}$ & $\begin{array}{l}\text { Movea } \\
\text { ble } \\
\text { sensor } \\
\text { s }\end{array}$ & 2 & $\begin{array}{l}\text { Connectivity not } \\
\text { considered }\end{array}$ \\
\hline$\stackrel{0}{-}$ & $\begin{array}{l}\text { Connecti } \\
\text { vity and } \\
\text { Coverage }\end{array}$ & $\begin{array}{l}\text { Direct } \\
\text { techniq } \\
\text { ue }\end{array}$ & $\begin{array}{l}\text { Senso } \\
\text { rs }\end{array}$ & $\begin{array}{l}\text { Movea } \\
\text { ble } \\
\text { sensor }\end{array}$ & 1 & $\begin{array}{l}\text { Multi-node and } \\
\text { simultaneous } \\
\text { node failures not } \\
\text { considered }\end{array}$ \\
\hline$=$ & $\begin{array}{l}\text { Connecti } \\
\text { vity }\end{array}$ & $\begin{array}{l}\text { Direct } \\
\text { techniq } \\
\text { ue }\end{array}$ & $\begin{array}{l}\text { Senso } \\
\text { rs }\end{array}$ & $\begin{array}{l}\text { Mobile } \\
\text { sensor } \\
\text { s }\end{array}$ & $1 \& 2$ & $\begin{array}{l}\text { Connectivity not } \\
\text { considered }\end{array}$ \\
\hline$\infty$ & $\begin{array}{l}\text { Connecti } \\
\text { vity } \\
\text { And } \\
\text { Network } \\
\text { Lifetime }\end{array}$ & $\begin{array}{l}\text { Shifted } \\
\text { techniq } \\
\text { ue }\end{array}$ & $\begin{array}{l}\text { Senso } \\
\mathrm{r}\end{array}$ & $\begin{array}{l}\text { Mobile } \\
\text { sensor } \\
\mathrm{s}\end{array}$ & 1 & $\begin{array}{l}\text { Multi-node and } \\
\text { simultaneous } \\
\text { node failures not } \\
\text { considered }\end{array}$ \\
\hline
\end{tabular}

\section{Comparison of Node Repositioning Techniques}

Dynamic node repositioning patterns comparison is shown in Table II. All the considered protocols are compared on the basis of various characteristics including optimization goals, migration techniques utilized during the operation, types of sensor nodes considered, the type of mobility of sensor nodes, the number of hops that are considered, and any limitations/constraints associated with the specific works. All the considered works are also provided with references so that if a reader is interested to know more details about a specific work, he/she can refer to the paper and read the full details.

\section{CONCLUSION}

A lot of research has been put into the Wireless Sensor Networks (WSNs) due to its immense potential for a variety of applications. However, the resource-limited sensor nodes, adhoc network formation, commonly coupled with the unattended procedure, leads to a number of challenges. One of such challenges is restoration of connectivity in case of failure of sensor nodes. This paper elucidates the influence of vibrant node repositioning in the sensor area by incorporating a series of methods and strategies from various researches done previously, that either subsequent to the process of deployment or through conventional operation of the network. Additionally, this research also signifies the number of technical problems encountered during node relocation, indicated as a resolution of the target of repositioning and evaluating the method of network management in relocating the nodes. Successively, numerous publications relating the techniques for dynamic node relocation have been interpreted together with the analysis followed by contemplation of the objective, mechanism, and implementation. A presumption developed here is that the mobile nodes can relocate dynamically in order for filling in the gap in interconnection and coverage and ultimately to cope with the changes. To sum up, the integrated multimode relocation issue has been described and this intriguing and challenging aspect has been elaborated.

\section{ACKNOWLEDGMENT}

We would like to express our gratitude to Najran University, Jouf University and King Khalid University for providing us administrative support and healthy research environment. This work is sponsored by Jouf University Saudi Arabia, under the research project number 40/117.

\section{REFERENCES}

[1] Y. Zhang, J. Wang, G. Hao, “An Autonomous Connectivity Restoration Algorithm Based on Finite State Machine for Wireless Sensor-Actor Networks", Sensors (Basel), 2018 doi: 10.3390/s18010153.

[2] Abbasi, A., Baroudi, U., Younis, M., Akkaya, K., "C2AM: An algorithm for Application-Aware Movement-Assisted Recovery in Wireless Sensor and Actor Networks". In Proceeding of the International Conference on Wireless Communications and Mobile Computing: Connecting the World Wirelessly, ACM, Leipzig, 2009.

[3] Akkaya K, Senel F, Thimmapuram A, and Uludag S. 2010. Distributed Recovery from Network Partitioning in Movable Sensor/Actor Networks via Controlled Mobility. IEEE Transactions on Computers 59(2):258-271.

[4] Chen, B., Jamieson, K., Balakrishnan, H., \& Morris, R., 2002. Span: An energy-efficient coordination algorithm for topology maintenance in ad hoc wireless networks. Wireless Networks, 8(5), 481-494. 
[5] Chen, J., Diaz, M., Llops, L., Rubio, B., \& Troya, J. M., 2011. A survey on quality of service support in wireless sensor and actor networks: Requirements and challenges in the context of critical infrastructure protection. Journal of Network and Computer Applications (Elsevier), $34,1225-1239$.

[6] Wang, G., G. Cao, T. La Porta, and W. Zhang, Sensor Relocation in Mobile Sensor Networks, in the Proceedings of the 24th Annual IEEE Conf. on Computer Communications (INFOCOM'05), Miami, FL, 2008

[7] Wang G, Cao G, Berman P, La Porta TF. Bidding protocols for deploying mobile sensors. IEEE Transactions on Mobile Computing. 2007 May;6(5):563-76.

[8] Wang, G., G. Cao, T. La Porta., 2004. Proxy-based sensor deployment for mobile sensor networks, in: Proceedings of the 1st IEEE International Conference on Mobile Ad-hoc and Sensor Systems (MASS'04), Fort Lauderdale, Florida.

[9] Hyewon, J., Wenrui Z, Mostafe H., Ellen W. Zeguar, Chungki L., 2007. Trading latency for energy in densely deployed wireless ad hoc networks using message ferrying, Journal of Ad Hoc Networks 2007; 5(4): pp. 444-61.

[10] Rizzo, A. G., Mancuso V., Ali S., Marsan, A M., Stop and forward: Opportunistic local information sharing under walking mobility, Ad Hoc Networks, Volume 78, 2018, Pages 54-72.

[11] Akyildiz, IF., W. Su, Y. Sankarasubramaniam, E. Cayirci., 2002.Wireless sensor networks: a survey," Computer Networks 38 (4), pp. 393-422.

[12] Chu, M., H. Haussecker, F. Zhao., 2010. Scalable information driven sensor querying and routing for ad hoc heterogeneous sensor networks, The International Journal of High Performance Computing Applications 16 (3), pp. 293-313.

[13] Younis, M., P. Munshi, E. Al-Shaer., 2003. Architecture for efficient monitoring and management of sensor networks, in: Proceedings of the IFIP/IEEE Workshop on End-to- End Monitoring Techniques and Services (E2EMON_03), Belfast, Northern Ireland, pp. 140-146.

[14] Younis, M., S. Lee, A. Abbasi., 2010. A Localized Algorithm for Restoring Internode Connectivity in Networks of Moveable Sensors, IEEE Transaction on Computers, Vol. 59, no. 12, pp 1669-1682.

[15] Heo. N., and P. K. Varshney., 2005. Energy-Efficient Deployment of Intelligent Mobile Sensor Networks. IEEE Trans. On Systems, Man, Cybernetics, Part A, Vol. 35, No. 1, pp. 117-127.

[16] Neelofer, T., Mohamed Y., 2010. Coverage-aware connectivity restoration in mobile sensor networks, Journal of Network and Computer Applications 33, pp. 363-374.

[17] Ma, Guizhen, et al. "Distributed connectivity restoration strategy for movable sensor networks." China Communications 11.13 (2014): 156163.

[18] Virender, R., Mayank, D., \& Kumar, V. A. "Lost Connectivity Restoration in Partitioned Wireless Sensor Networks." Proceedings of
International Conference on ICT for Sustainable Development. Springer Singapore, 2017.

[19] Yatish K. Joshi, Mohamed Younis, Feb, 2016 " Exploiting skeletonization to restore connectivity in a wireless sensor network." Computer communications vol.75, Issue C, pp. 97-107, Elsevier Science Publishers B. V. Amsterdam, The Netherlands.

[20] Akkaya, K. and Younis, M., 2007, April. C2AP: Coverage-aware and connectivity-constrained actor positioning in wireless sensor and actor networks. In 2007 IEEE International Performance, Computing, and Communications Conference (pp. 281-288). IEEE.

[21] Akkaya, Kemal, and Mohamed Younis. "Coverage and latency aware actor placement mechanisms in wireless sensor and actor networks." International Journal of Sensor Networks 3, no. 3 (2008): 152-164.

[22] M. Younis, S. Lee, S. Gupta and K. Fisher, "A Localized Self-Healing Algorithm for Networks of Moveable Sensor Nodes," IEEE GLOBECOM 2008 - 2008 IEEE Global Telecommunications Conference, New Orleans, LO, 2008, pp. 1-5.

[23] M. Younis and K. Akkaya, "Strategies and Techniques for Node Placement in Wireless Sensor Networks: A Survey ," The Journal of Ad-Hoc Network, 6(4): 621-655, 2008.

[24] G. Wang, G. Cao, T. La Porta, and W. Zhang, "Sensor Relocation in Mobile Sensor Networks," in the Proceedings of the 24th Annual IEEE Conf. on Computer Communications (INFOCOM'05), Miami, FL, Mar. 2005.

[25] Moh'd Alia, Osama. "Dynamic relocation of mobile base station in wireless sensor networks using a cluster-based harmony search algorithm." Information Sciences 385 (2017): 76-95.

[26] Ong, Keat Ghee, and Craig A. Grimes. "Network of sensor nodes assemblies and method of remote sensing within liquid environments." U.S. Patent No. 7,319,411. 15 Jan. 2008.

[27] A. Abro et al., "Minimizing Energy Expenditures using Genetic Algorithm for Scalability and Longlivety of Multi hop Sensor Networks," 9th International Conference on Electronics Information and Emergency Communication (ICEIEC), Beijing, China, 2019, pp. 183187.

[28] Arain. Q , et al., 2018. "Location monitoring approach: multiple mixzones with location privacy protection based on traffic flow over road networks". Multimedia Tools Appl. Vol 77, no 5.

[29] ul Hassan, Mahmood, Khan, M.A., Ali, S., Mahmood, K. and Shah, A.M., 2018. Distributed Energy Efficient Node Relocation Algorithm (DEENR). International Journal OF Advance Computer Science and Applications, 9(3), pp.95-100.

[30] Mahmood, K., Khan, M.A., Shah, A.M., Ali, S. and Saeed, M.K., 2018. Intelligent On-Demand Connectivity Restoration for Wireless Sensor Networks. Wireless Communications and Mobile Computing, 2018. 